\title{
A INFLUÊNCIA DOS MOVIMENTOS SOCIAIS PARA A CONSOLIDAÇÃO DO ACESSO À JUSTIÇA NO BRASIL: UM ESTUDO DE CASO DO MOVIMENTO NACIONAL DE LUTA CONTRA AIDS.
}

\author{
${ }^{1}$ Adriana Andrade Miranda \\ Silvana Beline ${ }^{2}$
}

\section{RESUMO}

A presente pesquisa, de cunho bibliográfica, visa apresentar uma experiência concreta de influência dos movimentos sociais na transformação do direito positivo e consequente na concretização do acesso à justiça no Brasil. $\mathrm{O}$ desenvolvimento foi estruturado em três partes: examinar o modelo de cientificidade dominante há dois séculos no mundo ocidental, apresentar uma crítica ao conceito de direito vigente e por fim analisar a atuação do movimento nacional de luta contra aids na garantia do acesso à justiça para pessoas vivendo com HIV/aids.

Palavras-chaves: Acesso À Justiça, Movimentos Sociais, Cidadania

\section{THE INFLUENCE OF SOCIAL MOVEMENTS FOR CONSOLIDATION OF ACESSO TO JUSTICE IN BRAZIL: A CASE STUDY OF THE NACIONAL MOVIMENT AGAINST AIDS}

\begin{abstract}
This bibliographic research presents a concrete experience on how social movements influence the transformation of law and the access to justice in Brazil. This research has three goals: to examine the dominant model of scientificity in the Western world over the last two centuries; to present a critique to the concept law; and to analise how the Brazilian national movement against AIDS guarantees access to justice to people with HIV/AIDS.
\end{abstract}

Keywords: Access To Justice, Social Movements, Citzenship

\footnotetext{
1 . Mestrada em Direito. Professora da Universidade Federal de Goiás - UFG - Goiás, (Brasil).

E-mail: adrianaandrade@terra.com.br

${ }^{2}$ Mestrada em Sociologia pela Universidade Estadual Paulista Júlio de Mesquita Filho - UNESP, São Paulo, (Brasil). E-mail: belinesilvana@gmail.com
}

e-ISSN: 2525-9830 | Curitiba | v. 2 | n. 2 | p. 1 - 22 | Jul/Dez. 2016. 


\section{APRESENTAÇÃO}

O presente estudo nasce de questionamentos comumente feito pelos movimentos sociais: "a quem cabe 'dizer o direito'?" "nós (movimentos sociais) não podemos 'dizer o direito'?".

Se para teoria tradicional do direito a lei encontra seu fundamento na própria lei, numa tentativa de afastá-lo ao máximo das pressões sociais, diversos autores já apontam a importância dos movimentos sociais para transformação e efetivação de direitos e consequente para concretização do acesso à justiça. Entre esses autores podemos destacar Roberto Lyra Filho, Boaventura de Sousa Santos e José Geraldo de Sousa Junior.

Para Bourdieu (2005), o debate jurídico acerca do direito é dominado por duas características: formalismo e instrumentalismo. O formalismo afirma a autonomia da forma jurídica em relação ao mundo social e o instrumentalismo concebe o direito como um reflexo a serviço dos grupos sociais dominantes. Nesta perspectiva o direito é um sistema fechado e autônomo, cujo desenvolvimento só pode ser compreendido a partir de sua própria dinâmica interna de funcionamento. Esta reivindicação por autonomia do pensamento e ação jurídica visam libertá-los do "peso social". Este modelo de direito - positivismo jurídico - está diretamente ligado ao modelo de cientificidade que pressupõe a neutralidade, objetividade e possibilidade de verificação como requisitos para se alcançar a verdade.

A doutrina positivista do Direito pressupõe a identidade entre direito e estado, estabelecendo que para ser legítimo o "direito" precisa estar positivado. Isso significa que apenas um sistema de direito é reconhecido com válido, o sistema estatal, e que apenas pessoas autorizadas por este mesmo sistema podem "dizer" o que é direito, ou seja, legisladores e juristas. Sistema de direitos portanto, se confunde com sistema legal, havendo uma associação direta entre direito e norma. Isso significa que o direito vigente, válido, legítimo, é produzido pelo Estado, livre das pressões sociais e espelho dos interesses dos

\footnotetext{
e-ISSN: 2525-9830 | Curitiba | v. 2 | n. 2 | p. 1 - 22 | Jul/Dez. 2016.
} 
grupos sociais que estão no poder. $\mathrm{O}$ acesso à justiça por sua vez, restringe-se a reivindicação judicial dos direitos positivados, sendo o Estado, por meio do poder judiciário, o único autorizado a "dizer o direito".

Contudo, a luta em prol dos direitos humanos mudou este cenário e as lutas sociais, sobretudo as que ocorreram a partir da década de 70, foram responsáveis por mudanças nas estruturas jurídicas. Os movimentos sociais no Brasil assumem o protagonismo na construção e efetivação do direito e direito à saúde, direito à moradia, luta pela terra, dignidade no trabalho, igualdade de gênero e de raça são alguns dos temas que destacam nesse período. A Assembleia Nacional Constituinte é o ápice desse processo de reivindicações por novos direitos, que culminou com a positivação - e posteriormente em novas interpretações - de novas categorias legais, como é o caso, por exemplo, do novo conceito de direito à saúde inscrito na Constituição de 1988.

Essa nova dinâmica de reivindicação do direito de dizer o direito ficou conhecida nas categorias cunhadas por José Geraldo de Sousa Junior e Roberto Lyra Filho, respectivamente: direito achado na rua e direito como positivação em luta por princípios libertadores.

A presente pesquisa, de cunho bibliográfica, visa apresentar uma experiência concreta de influência dos movimentos sociais na reivindicação de direitos e concretização do acesso à justiça no Brasil. O percurso será dividido em três etapas que consistirão em: examinar o modelo de cientificidade dominante há dois séculos no mundo ocidental, apresentar uma crítica ao conceito de direito vigente e por fim analisar a ação do movimento nacional de luta contra aids na ressignificação do conceito de direito à saúde e sua garantia para pessoas vivendo com HIV/aids.

2. Crítica ao modelo de racionalidade dominante - a contribuição de Boaventura de Sousa Santos 
Boaventura de Sousa Santos (2003) faz uma crítica a redução do direito ao direito estatal, mostrando que esta concepção estreita e restritiva do direito é fruto do modelo de racionalidade dominante, do processo de globalização hegemônica ${ }^{3}$ e da necessidade de supressão de identidades para o pleno desenvolvimento do capitalismo. Nos últimos dois séculos, os debates filosóficos e epistemológicos têm sido comandados no Ocidente por um modelo de racionalidade que transforma interesses hegemônicos em conhecimentos verdadeiros, gerando aniquilamento, alienação e violência. O advento do capitalismo, a consolidação do Estado Liberal, as revoluções industriais, o colonialismo e o imperialismo deram as bases sociais e políticas para o desenvolvimento deste modelo.

Boaventura de Sousa Santos faz uma crítica a este modelo de racionalidade, a que chama de razão indolente, partindo de três os pressupostos: 1) a experiência social em todo mundo é muito mais ampla e variada do que a tradição científica ou filosófica ocidental reconhece; 2) o desperdício dessas experiências sociais "não válidas"; e 3) a inutilidade do modelo de ciência moderna para combater esse desperdício e tornar visíveis as iniciativas e os movimentos alternativos. Assim, o sociólogo português propõe um novo modelo, denominado razão cosmopolita.

3 O termo globalização hegemônica é definido aqui como uma globalização de cima para baixo ou globalização neoliberal. Boventura de Sousa Santos se refere a dois processo processo inerentes a globalização hegemônica: localismo globalizado: ou seja, processo em que determinado fenômeno local é globalizado com sucesso e o globalismo localizado, em que o impacto específico de práticas e imperativos transnacionais nas condições locais gerando desestruturação e restruturação para responder a esses imperativos (agricultura de exportação, turismo etc). Para fazer frente a esse processo de globalização é preciso um processo de cosmopolitismo que pressupõe articulações que movimentos, entidades, organizações visando combater o globalismo localizado e o localismo globalizado (Fórum social Mundial, Redes de diálogo sul-sul etc) (SANTOS, 2003). 
O ponto de partida da razão cosmopolita é a valorização das múltiplas e diversas experiências sociais em curso no mundo. Para tanto defende a necessidade de se realizar uma sociologia das ausências e uma sociologia das emergências, através de um minucioso e cuidadoso trabalho de tradução. Pretende-se assim identificar e tornar visível as experiências ignoradas pela racionalidade dominante e fomentar o diálogo entre essas experiências, sem, contudo, destruir suas identidades. (SANTOS, 2003)

\subsection{A razão indolente}

A razão indolente, segundo Santos (2004) é a forma como o ocidente percebe as relações sociais, e sua principal característica é a universalização de seus paradigmas. Além disso, é importante ressaltar que sua capacidade de transformar em verdade apenas o que interessa ao sistema capitalista e ocultar distintas e variadas compreensões de vida tem fortalecido o processo de globalização hegemônica em todo mundo. E é justamente porque restringe a compreensão do mundo à compreensão ocidental do mundo, que a razão indolente se caracteriza como uma razão parcial e seletiva.

Essa parcial e seletiva compreensão das relações sociais gerou violência, submissão e alienação. A arrogância da razão indolente é obstáculo para a valorização das experiências que não servem para o desenvolvimento do capitalismo, empobrecendo as formas de entender o mundo e a vida.

Para recuperar a experiência desperdiçada é preciso ampliar o mundo, através da valorização da diversidade e multiplicidade de formas de viver e entender o mundo. É preciso proporcionar uma convivência harmoniosa entre todas as diferentes experiências, para além das relações de poder. Isso implica o resgate das subjetividades ocultadas, através de uma sociologia das ausências e uma sociologia das emergências. 


\subsection{A Sociologia das ausências e a Sociologia das emergências}

A sociologia das ausências proposta por Santos (2004) visa "revelar a diversidade e multiplicidade das práticas sociais e credibilizar esse conjunto por contraposição à credibilidade exclusiva das práticas hegemônicas" (2004:794). É uma investigação que visa demonstrar que o que não existe é, na verdade, produzido como não existente. Seu objetivo é "transformar objetos impossíveis em possíveis e com base neles transformar as ausências em presenças" (SANTOS, 2004, p.794). A sociologia das emergências por sua vez se propõe "substituir o vazio do futuro segundo o tempo linear (um vazio que tanto é tudo como é nada) por um futuro de possibilidades plurais e concretas, simultaneamente utópicas e realistas, que se vão construindo no presente através das actividades de cuidado" (2004:794). Ambas contribuem para aumentar o acumulo de experiências sociais e para acabar com as formas de produção da não existência ${ }^{4}$.

São cinco categorias de não existência produzidas ou legitimadas pela razão indolente: o ignorante, o residual, o inferior, o local e o improdutivo. Essas categorias são atribuídas em função de um só critério que não admite ser questionado por qualquer outro critério

4 Todas as formas de produção de não existência são manifestações de uma mesma monocultura racional. São cinco os tipos de monocultura racional apresentados pelo autor: 1)monocultura do saber e do rigor do saber: transformação da ciência moderna e da alta cultura em critérios únicos de verdade e de qualidade estética, respectivamente. A não existência significa ignorância ou incultura; 2) monocultura do tempo linear: a história tem sentido e direção únicos e conhecidos, formulados de diversas formas - modernização, progresso, , revolução, desenvolvimento, crescimento, globalização. Esta direção da história é capitaneada pelos países centrais do sistema mundial, e tudo o que é assimétrico em relação ao que é considerado avançado é considerado atrasado; 3) lógica da classificação social ou monocultura da naturalização das diferenças. Consiste na distribuição da população em categorias que naturalizam as hierarquias (classificação racial e sexual por exemplo); 4)lógica da escala dominante: universal e global X particular e local. Predominância do primeiro sobre o segundo; 5) lógica produtivista ou monocultura dos critérios de produtividade capitalista: o crescimento econômico é um objetivo inquestionável e o melhor sistema que serve a este objetivo é o sistema capitalista. (SANTOS, 2004). 
A Influência dos Movimentos Sociais para a Consolidação do Acesso à Justiça no Brasil: Um estudo de Caso do Movimento Nacional de Luta Contra aids.

alternativo. São partes desqualificadas da totalidade homogênea que confirmam o que existe e como existe. A não existência gera ausência e representa opressão, supressão, alienação e exclusão. Não se pretende acabar com essas categorias, através da sociologia das ausências, mas apenas que elas deixem de ser atribuídas a partir de um único critério. (SANTOS, 2004)

A produção social destas ausências resulta na subtração do mundo e na contração do presente e, portanto, no desperdício da experiência. A sociologia das ausências visa identificar o âmbito dessa subtração e dessa contração de modo a que as experiências produzidas como ausentes sejam libertadas dessas relações de produção e, por essa via, se tornem presentes. Tornar-se presentes significa serem consideradas alternativas às experiências hegemónicas, a sua credibilidade poder ser discutida e argumentada e as suas relações com as experiências hegeomónicas poderem ser objeto de disputa política. A sociologia das ausências visa, assim, criar uma carência e transformar a falta de experiência social em desperdício da experiência social. (SANTOS, 2004, p.789)

Para superar essas totalidades homogêneas e excludentes e produtoras da não existência, Boaventura propõe cinco procedimentos de resgate e valorização da diversidade multiplicidade das experiências sociais, a que chama de Ecologia: dos saberes, das temporalidades, do reconhecimento, das trans escalas e da produtividade. ${ }^{5}$

5 Ecologia dos saberes: reconhecimento e identificação de outros saberes e de outros critérios de rigor que operam credivelmente em contextos e práticas sociais declarados não-existentes pela razão metonímica. Ecologia das temporalidades: ideia de que o tempo linear é apenas uma entre muitas concepções do tempo. Parte da ideia de que as sociedades são constituídas por várias temporalidades e de que a desqualificação, supressão ou inteligibilidade de muitas práticas resulta de se pautarem por temporalidades que extravasam do cânone temporal da modernidade ocidental capitalista. Ecologia dos reconhecimentos: procurar uma nova articulação entre o princípio da igualdade e o princípio da diferença e abrindo espaço para a possibilidade de diferenças iguais uma ecologia de diferenças feita de reconhecimentos recíprocos. Desconstruir tanto a diferença como a hierarquia, questionando em que medida a diferença é produto da hierarquia e vice-versa. Ecologia das trans escalas: recuperação no local do que não é feito pela globalização hegemônica. Ecologia de produtividade: recuperar e valorizar os sistemas alternativos de produção, das organizações econômicas populares, das

e-ISSN: 2525-9830 | Curitiba | v. 2 | n. 2 | p. 1 - 22 | Jul/Dez. 2016. 
A prática desses procedimentos implica um exercício de imaginação que o sociólogo português denominou de imaginação epistemológica e imaginação democrática. A imaginação epistemológica nos permite diversificar os conteúdos e procedimentos de análise. A imaginação democrática por sua vez, nos auxilia a reconhecer diferentes práticas e atores sociais. São exercícios complementares que juntos possibilitam a ampliação e o resgate das diferentes formas de compreender o mundo. É este exercício de imaginação que nos possibilitará desconstruir os pressupostos da razão indolente ao mesmo tempo em que nos auxiliará na construção das bases para a razão cosmopolita.

Santos (2004) apresenta ainda cinco campos sociais que considera mais importantes e onde acredita que a multiplicidade e a diversidade se revelarão com maior probabilidade. São eles: experiências de conhecimento, experiências de desenvolvimento, experiências de reconhecimento, experiências de democracia, experiências de comunicação e de informação. ${ }^{6}$

Para se conseguir realizar com êxito uma sociologia das ausências e uma sociologia das emergências, desvelando a complexa teia social sem incorrer nos mesmos erros que a razão indolente, é necessário um cuidadoso trabalho de tradução.

cooperativas operaria etc, que a ortodoxia produtivista capitalista ocultou ou descredibilizou. Reconstruir essas formas para além da subalternidade. (SANTOS, 2004)

6 Experiências de conhecimento: conflitos e diálogos possíveis entre diferentes formas de conhecimento. Experiências de desenvolvimento, trabalho e produção: diálogos e conflitos possíveis entre diferentes formas e modos de produção diferentes. Experiências de reconhecimento: diálogos e conflitos possíveis entre sistemas de classificação social. Experiências de democracia: diálogos e conflitos possíveis entre o modelo hegemônico de democracia (representativa liberal) e a democracia participativa. Experiências de comunicação e de informação: diálogos e conflitos possíveis, derivados da revolução das tecnologias de comunicação e de informação, entre fluxos globais de informação e os meios de comunicação social globais, por um lado, e, por outro, as redes de comunicação independente e transnacionais e os media independentes alternativos. (SANTOS, 2004)

\section{e-ISSN: 2525-9830 | Curitiba | v. 2 | n. 2 | p. 1 - 22 | Jul/Dez. 2016.}


A tradução aqui proposta procura identificar a interseção entre preocupações isomórficas das diferentes culturas e as respostas que fornecem a elas. Isso significa captar a relação hegemônica entre as experiências e o que nestas está para além da relação de poder. Ela incide tanto sobre os saberes como sobre as práticas e parte da ideia de que todas as culturas são incompletas e, portanto, podem ser enriquecidas pelo diálogo e pelo confronto com outras culturas.

O trabalho de tradução visa esclarecer o que une e o que separa os diferentes movimentos e as diferentes práticas, de modo a determinar as possibilidades e os limites da articulação ou agregação entre eles. Dado que não há uma prática social ou um sujeito colectivo privilegiado em abstrato para conferir sentido e direção à história, o trabalho de tradução é decisivo para definir, em concreto, em cada momento e contexto histórico, quais as constelações de práticas com maior potencial contra hegemônico. (SANTOS, 2004, p.806)

O objeto da tradução, ou seja, a seleção dos saberes e práticas entre os quais se realiza o trabalho de tradução é sempre resultado de uma convergência ou conjugação de sensações de experiências de carência, de inconformismo, e da motivação para as superar de uma forma específica. O momento de traduzir deve ser uma conjugação de tempos, ritmos e oportunidades, conforme nos ensina o sociólogo português.

O trabalho de tradução é complementar ao trabalho das sociologias das ausências e das emergências. Se estas últimas aumentam o número e diversidade de experiências disponíveis e possíveis, o trabalho de tradução cria a inteligibilidade, coerência e articulação num mundo enriquecido pela multiplicidade e diversidade das experiências.

A razão indolente, ao reduzir o mundo a concepção ocidental do mundo e ao considerar como válidas apenas as experiências que servem ao desenvolvimento do sistema 
capitalista, fortaleceu o movimento positivista do direito que considera válido apenas o direito estatal. Com isso todas as demais formas de organização e regulação social foram suprimidas, assim como as necessidades, anseios e reivindicações das diferentes culturas e grupos sociais.

Assim, uma nova concepção acerca do direito, que compreenda sua vertente teórica e prática, genuinamente comprometida com a emancipação dos grupos socialmente excluídos e que valorize as compreensões, anseios e revindicações de direitos desses grupos se faz necessária como estratégia de enfrentamento à razão "jurídica" indolente na construção de um conhecimento prudente para uma vida decente.

\section{Do monismo ao pluralismo - a crítica ao Direito de Roberto Lyra Filho e a contribuição teórico prática de O Direito Achado na Rua}

Roberto Lyra Filho foi responsável pela criação de uma teoria crítica do direito capaz de dar voz aos movimentos sociais. Nos seus textos Lyra Filho defende um direito da libertação, que seja a legitima organização da liberdade, livre dos dogmas que o torna estático, e que esteja a serviço dos interesses dos grupos espoliados. Assim, o autor rompe com a visão positivista do direito e sua consequente associação ao Estado, propondo um alargamento do próprio conceito de direito, uma substituição da teoria monista do direito por uma teoria pluralista do direito.

No manifesto "Para um direito sem dogmas" Lyra Filho (1980) proclama a morte da dogmática, ao tempo em que demonstra suas ressurreições ao longo da história. A dogmática era repudiada por revolucionários que reivindicavam a instauração de uma nova ordem jurídica, por exemplo, e ressuscitada uma vez instalada a nova ordem. É o caso da Revolução Francesa e Revolução Russa. A dogmática era usada para justificar os interesses da classe dominante, através da crença absoluta e inquestionável nas normas. 
O amadurecimento da chamada ciência (dogmática) do Direito representou o correspondente impulso ideológico da ascensão da burguesia. Aquele jusnaturalismo da Idade Média, com seu anquilosado teor de natureza fixista, fora banido pelo jusnaturalismo racional, que constituía a arma ideológica para a escalada da burguesia. (LYRA FILHO, 1980, p.19)

Lyra Filho defende (1982) que o direito é eterno estado de devenir, se constrói e se transforma a partir da dialética entre o conflito e o consenso. A redução do direito ao direito estatal representa uma paralisação da dinâmica desta dialética social. Ao mesmo tempo, afirma que o direito se revela na norma, mas a ele não se restringe. $\mathrm{O}$ que determina a legitimidade da norma é o processo social. A norma é apenas uma das expressões do direito, o instrumento que materializa o direito. A essência do direito só pode ser encontrada nas relações sociais que são dinâmicas e complexas. Este dinamismo que torna o direito um eterno devenir, em eterna mutação.

\begin{abstract}
'Todos os movimentos sociais (...) fundaram-se num direito, que exprimia a sua posição e reivindicação' (BOURJOL, 1978:127) Esse direto não é mais, evidentemente, um decálogo de máximas eternas, porém a definição de aspirações, necessidades, exigências dos oprimidos. A história contemporânea oferece-nos muitos exemplos disto: as lutas de libertação nacional com o direito à independência; as reivindicações das minorias étnicas ou raciais, exigindo a igualdade; e ainda outras minorias (regionais, sexuais). (1980:18)
\end{abstract}

As doutrinas clássicas do direito - a teoria monista - não comportam essas formas jurídicas em devenir, nem comportam os fenômenos da realidade em processo. A segurança jurídica e estabilidade social são os grandes argumentos que justificam essa refutação e dissimulam as relações de poder que permeiam a produção do direito. $\mathrm{O}$ foco dedutivo do 
direito parte do Estado. Ou seja, para saber o que é direito é preciso investigar o que o Estado pensa que é o Direito. Importante notar que o Estado é uma ficção criada pelos próprios homens. São os homens que compõe o Estado, logo são os homens que determinam o que é ou não direito. As relações de poder e hierárquicas entre os próprios homens são, portanto determinantes para se definir o que é ou não direito (LYRA FILHO, 1982).

O positivismo jurídico muito se assemelha ao positivismo sociológico, diz Roberto Lyra Filho (1982), pois ambos partem do modelo de sociologia centrípeta, ou seja, o controle social e a cultura dominante são o ponto de partida para dominar e ocultar as subculturas e coibir qualquer contestação ao modelo vigente. Ou seja, esses dois modelos de positivismo estão diretamente associados ao modelo de racionalidade denominado por Boaventura de Sousa Santos como razão indolente.

Entretanto, a afirmação de que o direito válido é apenas o direito positivo pressupõe a existência de outros direitos que não são positivos mas que são direito. Se assim não fosse o direito dispensaria o adjetivo de positivado. Estes outros direitos, são justamente as aspirações, anseios, desejos e reivindicações de diferentes movimentos sociais que lutam pela efetivação dos direitos humanos no mundo. São também formas de viver, produzir e se relacionar de povos e culturas que por razões históricas foram alijadas das instâncias decisórias e de poder e do direito de autodeterminação, como por exemplo ocorreu com povos indígenas na América.

A dinâmica social é composta tanto pela necessidade de regulação (padrões de controle social) como pelo impulso transformador. O direito não pode ser separado da realidade social. Isto significa confiná-lo ao que os grupos no poder dizem que é direito, estabelecendo uma relação de opressão e aniquilamento de culturas e identidades. O sistema jurídico precisa ser compreendido não apenas como abstração acadêmica, mas antes de tudo como criação viva que brota no solo social (LYRA FILHO, 1980). 
A Influência dos Movimentos Sociais para a Consolidação do Acesso à Justiça no Brasil: Um estudo de Caso do Movimento Nacional de Luta Contra aids.

Essa concepção de direito que nas palavras de José Geraldo de Sousa Junior (2008) “emerge, transformadora, dos espaços públicos", inspira a corrente teórico prática intitulada O Direito Achado na Rua, movimento iniciado por Roberto Lyra Filho e consolidado por José Geraldo de Sousa Junior, comprometida com a construção de uma cultura democrática e de participação social.

Esta proposta está imbuída de um claro humanismo, pois toma o protagonismo dos sujeitos enquanto disposição para quebrar as algemas que os aprisionam nas opressões e espoliações como condição de desalienação e de possibilidade de transformarem seus destinos e suas próprias experiências em direção histórica emancipadora, como tarefa que não se realiza isoladamente, mas em conjunto, de modo solidária. (SOUSA JUNIOR, 2008, p. 05)

O Direito achado na Rua, enquanto matriz teórico-prática de análise do fenômeno jurídico e de aprendizagem do direito, permite que reconheçamos experiências sociais de reivindicação de direitos e acesso à justiça genuinamente comprometidas com a cidadania e a democracia.

Sousa Junior (2007) caracteriza O Direito Achado na Rua como um processo de aprendizagem do direito a partir das experiências sociais. Fábio de Moraes Sá e Silva (2007) aponta os pressupostos desse processo:

a) determinar o espaço político no qual se desenvolvem as práticas sociais que enunciam direito ainda que contra legem; b) definir a natureza jurídica do sujeito coletivo capaz de elaborar um projeto político de transformação social e elaborar a sua representação teórica como sujeito coletivo de direito; e c) enquadrar os dados derivados destas práticas sociais criadoras de direitos e estabelecer novas categorias jurídicas para estruturar as relações solidárias de uma sociedade alternativa em que sejam superadas as condições de espoliação e de opressão do homem pelo homem e na qual o direito possa realizar-se como um projeto de legítima organização da liberdade. (2007:97)

e-ISSN: 2525-9830 | Curitiba | v. 2 | n. 2 | p. 1 - 22 | Jul/Dez. 2016. 
Roberto Ramos Aguiar (2002) também apresenta os pressupostos teóricos de O Direito Achado na Rua:

O Direito Achado na Rua situa a juridicidade como fenômeno a ser estudado pelos instrumentos das ciências sociais. O Direito não é uma ciência normativa-ética, nem é uma ciência das normas postas. $\mathrm{O}$ direito tem de trabalhar com a globalidade do ser humano, imerso e atuando na concretude da história, nas contradições da sociedade e nos conflitos existenciais e materiais que a condição humana impõe. A fonte e o destinatário dos preceitos jurídicos é o cidadão; o estado é um dos instrumentos (o hegemônico) para a realização desse direito. [...] o direito passa a ser plural. Não mais um ordenamento jurídico sacralizado pelo Estado, mas vários ordenamentos em luta, pois os despossuídos, os dominados, na medida em que se organizam, criam direitos paralelos e forçam o direito hegemônico a se modificar, ou mesmo a desaparecer, no caso de uma revolução. Por isso à preocupação do Direito Achado na Rua com o direito de resistência, com a classificação das diferenças entre revolução e reforma, com a legitimidade, a soberania popular e a cidadania. Essa visão obriga, cientificamente, o estudo dos novos sujeitos de direito. Não mais aquela estrita individualidade, mas o ser humano coletivamente organizado, conquistando espaços jurídicos-políticos na sociedade conflitiva. (2002:53)

O Aguiar destaca ainda a importância dos direitos humanos para O Direito Achado na Rua, entendo os direitos humanos enquanto "bandeiras e princípios decorrentes das lutas históricas, que devem ser definidos e ampliados pelo exercício vigilante e permanente da cidadania organizada a ser fundamentados em valores que sobrepassam as interpretações restritas das normas positivas" (2002:54).

Cláudio Souto (2002), refletindo sobre o direito estatal e sobre O Direito Achado na Rua reconhece a rua como lugar legítimo de produção do direito que corresponda às necessidades fundamentais do homem. E, nesse sentido, a rua é o lugar legítimo porque é nela que se encontram os "excluídos, os arremessados sobre as calçadas por uma economia capitalista de lucro, longe de beneficiar a todos" (2002:63). Além disso, destaca o autor, "a rua é palco dramático, sobretudo nos países periféricos, de necessidades humanas básicas não

\section{e-ISSN: 2525-9830 | Curitiba | v. 2 | n. 2 | p. 1 - 22 | Jul/Dez. 2016.}


atendidas pelo Estado e pela sociedade, portanto, palco sombrio de direitos negados por ação ou omissão" (2002: 64).

O movimento nacional de luta contra aids se enquadra nessa categoria uma vez que sua atuação se relaciona com a efetivação do direito à saúde - constitucionalmente assegurado - oferecendo um nova olhar sobre esse direito e desnudando os limites da atuação jurídica tradicional pautada pela judicialização de demandas.

\section{Os atores sociais em ação - o movimento nacional de luta contra a aids e a efetivação do direito fundamental à saúde}

O vírus HIV/aids surgiu no final da década de 70. Por ser uma doença cuja principal forma de transmissão é a sexual, estigmas foram lançados sobre os portadores do vírus, e por ser uma doença incurável, o diagnóstico era o prenúncio da morte. A aids trouxe ao mundo não somente mais uma doença considerada sem cura, ela nos apresentou a um fator de total rediscussão de conceitos, preconceitos e comportamentos dos indivíduos. Questões consideradas tabus como por exemplo comportamento sexual, uso de drogas ilícitas, a profissionalização do sexo foram incluídas na ordem do dia, gerando reflexos para diversas áreas do conhecimento humano (MIRANDA, 2007).

O primeiro grupo vitimado pela aids foram os homossexuais masculinos, de classe média e/ou média alta, tornando a doença conhecida como "peste gay", estigmatizando ainda mais um grupo vítima de grandes discriminações. A estes se seguiram as/os profissionais do sexo e usuários de drogas injetáveis, aumentando a estigmatização em torno da doença e seus portadores, que passaram a ser identificados como "grupos de risco".

O preconceito dificultou, no início da epidemia, o reconhecimento imediato de direitos aos soropositivos. Grupos religiosos consideravam a doença um castigo divino e propagavam ideias contra o direito das pessoas vivendo com aids. As violações de direitos eram constantes e de natureza distintas. Recusa no atendimento médico-hospitalar, segregação social, 
esterilização e aborto compulsório de mulheres soropositivas, são alguns exemplos dos principais problemas enfrentados pelas pessoas com HIV/aids.

Paralelo ao início da epidemia, o Brasil enfrentava o processo de redemocratização que possibilitou o surgimento de inúmeras organizações não governamentais, com diferentes linhas de atuação, tendo em comum a luta por acesso à justiça, direitos humanos e efetivação dos direitos sociais. A promulgação da $\mathrm{CF} / 88$ deu fôlego a luta pelos direitos humanos no Brasil e para o fortalecimento da sociedade civil organizada.

A saúde é um tema central na nossa sociedade por estar relacionada intrinsecamente com a dignidade e com a vida. Fruto de forte pressão social de movimentos sociais, em especial do movimento sanitarista, o direito à saúde foi alçado a categoria de direito fundamental pela Constituição Federal de 1988, previsto nos artigos 196 e 197, sendo esta definida como "direito de todos e dever do Estado, garantido mediante políticas sociais e econômicas que visem à redução do risco de doença e de outros agravos e ao acesso universal e igualitário às ações e serviços para sua promoção, proteção e recuperação". Ou seja, o conceito de saúde foi alargado, incorporando além dos aspectos médicos, condições econômicas, culturais e sociais dignas. Tal conceito se coaduna com o que determina a Organização Mundial de Saúde - OMS que define saúde como "um estado de completo bemestar físico, mental e social, e não consiste apenas na ausência de doença ou de enfermidade".

Nessa perspectiva, o direito à saúde possibilita o redimensionamento dos direitos humanos, na medida em que a saúde é um dos mais importantes e significativos direito que o cidadão possui. O direito à saúde implica no direito de cuidar de si mesmo e do outro, e no direito de ser cuidado. Relaciona-se com o afeto, com a esperança, com a utopia, com o desejo e com o sonho. Uma sociedade que não garante o direito à saúde de seus cidadãos, é uma sociedade que cria obstáculos a sua própria transformação, pois castra a esperança. E sem esperança não existe força para mudanças estruturais e simbólicas.

e-ISSN: 2525-9830 | Curitiba | v. 2 | n. 2 | p. 1 - 22 | Jul/Dez. 2016. 
Apesar de ser uma garantia constitucional, a efetivação do direito à saúde é um desafio e encontra barreiras, muitas vezes difíceis de serem transpostas. No caso de doenças epidêmicas, em especial a aids, o maior obstáculo é o preconceito, pelo seu enorme poder castrador, que reduz o doente à doença. A pessoa infectada pelo vírus da aids torna-se "aidético", "portador do vírus HIV”, "soropositivo", e as demais subjetividades (ser homem, mulher, negra, branca, heterossexual, homossexual) são anuladas.

É neste contexto, de abertura política, nova ordem constitucional e recusa no reconhecimento do direito de soropositivos, que surgem as organizações não governamentais de luta contra a aids, reivindicando o reconhecimento do direito e acesso à justiça dos soropositivos e a implementação de políticas públicas concretas e eficazes de assistência às pessoas vivendo com HIV/aids e de prevenção à doença.

A efetivação do direito à saúde das pessoas com HIV/aids significa não só o acesso ao tratamento adequado, mas também, acesso ao trabalho, a convivência social, à maternidade, ao lazer, à intimidade, à privacidade. Em virtude do preconceito e da discriminação o "bemestar físico e mental" liga-se intrinsecamente ao convívio social, à qualidade de vida, ao exercício da cidadania, ao afeto, ao respeito e ao direito de sonhar e lutar por uma sociedade mais justa e igualitária.

A Lei 9313/96 (lei Sarney), fruto de forte pressão popular, garantiu a distribuição gratuita e universal de medicamentos antirretrovirais para os portadores de HIV/aids, representando um grande avanço na luta pela qualidade de vida das pessoas vivendo com HIV/aids (CARNEIRO, 2002, p.24). Contudo, as pessoas vivendo com HIV/aids continuam carentes de uma rede de serviços básicos de atenção e espaços de socialização e discussão de direitos que possam responder às dificuldades inerentes a sua condição sorológica. $\mathrm{O}$ preconceito continua sendo um obstáculo para o efetivo reconhecimento do direito à saúde e o efetivo acesso à justiça de pessoas vivendo com HIV/aids. 
A luta do movimento nacional de luta contra a aids consiste em compreender a relação entre saúde e combate ao preconceito, ou seja, na importância de vencermos o preconceito como estratégia de garantia da efetivação do direito à saúde ${ }^{7}$. Afinal, como prevê a constituição, assegurar a saúde da cidadã e do cidadão significa garantir o seu completo bemestar físico, psíquico, econômico e social. Nesse sentido, estratégias de construção de significados do direito são importantes para se alcançar a plena realização dos direitos fundamentais das pessoas vivendo com HIV/aids. Compreender que a realização do direito à saúde implica diretamente no combate ao preconceito e não apenas nas políticas de distribuição de medicamentos. Nesse contexto, a judicialização de demandas mostrou-se limitada para oferecer as respostas necessárias para efetivação do direito.

Segundo Capelletti (2002) o acesso à justiça passou por três fases: a) assistência judiciária; b) ampliação do acesso ao judiciário dos direitos difusos e coletivos; c) remoção de obstáculos que existem ao pleno e efetivo acesso à justiça.

No mesmo sentido Rocha (2011) destaca:

Por acesso à justiça tem se entendido, majoritariamente, por princípio constitucional que fundamenta o direito de acesso aos tribunais, o direito de recorrer da violação de direito subjetivo. Tal acepção está em perfeita sintonia com o Estado Democrático, que deve ser erguido segundo o mandamento da Constituição em seu art. Todavia, o acesso à justiça, no nosso sentir, abarca outras características além da dimensão processual. (2001:03)

7 Segundo Mauro Cappelletti (2004) o acesso à justiça passou por três fases. A primeira fase, também conhecida como conceito clássico de acesso à justiça é caracterizada pela assistência judiciária que, atualmente, está prevista no art. $5^{\circ}$, inciso LXXIV, da Constituição Federal. A segunda fase é caracterizada pela judicialização de demandas relacionadas aos interesses difusos e coletivos. A terceira fase implica no alargamento do conceito de acesso à justiça, ou seja no enfrentamento de obstáculos que ainda existem para a sua plena realização. 
No que toca ao acesso à justiça de pessoas vivendo com HIV/aids, percebemos a experimentação das três fases indicadas por Capelletti (2002) bem como a necessidade de pensar novas dimensões como indicado por Rocha (2011).

As primeiras ações propostas tiveram caráter individual sendo que muitas delas rapidamente se converteram em ações coletivas a partir da compreensão do potencial difuso do direito à saúde. A judicialização de demandas pressupõe, no contexto da aids, um esforço interpretativo que reside em oferecer significados alargados aos conceitos jurídicos em busca de respostas para a complexa e intricada relação entre saúde e preconceito.

O Poder Judiciário, entretanto, mostrou-se limitado para responder aos desafios impostos pela epidemia, sobretudo no que diz respeito ao combate ao preconceito (MEDEIROS, 2002, P.38). O despreparo dos seus integrantes para lidar com as questões morais, éticas e sociais relacionadas à aids, a concepção positivista que domina a cultura jurídica brasileira e a repercussão limitada da ação judicial individual, constituem-se óbices à plena realização do acesso à justiça e do direito à saúde no Brasil.

Garantir o direito à saúde de pessoas vivendo com HIV/aids, ou qualquer outra doença estigmatizante, portanto, implica exercer fundamentalmente o "direito de dizer o que é direito", ou seja, implica em um esforço de alargamento dos conceitos jurídicos e a compreensão de que a efetivação do direito exige estratégias para além da judicialização de demandas, e que o preconceito é um obstáculo real para a garantia do acesso à justiça e para efetivação de direitos.

Nesse sentido, ações educativas, de esclarecimento, conscientização e valorização do indivíduo são fundamentais no combate ao preconceito e discriminação, na efetivação do direito à saúde e se convertem também em estratégias de acesso à justiça. 


\section{Considerações finais}

Existem inúmeras experiências em todo país de lutas sociais pela garantia do acesso à justiça e reconhecimento de direito de grupos socialmente vulneráveis, com estratégias diversificadas de ressignificação dos conceitos jurídicos com reflexos na produção, criação e aplicação do direito.

Como vimos ao longo do texto, muitos são os obstáculos que impedem a abertura do mundo jurídico aos novos atores sociais. As barreiras encontram-se tanto no modelo de cientificidade como na concepção de direito, sendo que esta última é consequência do primeiro.

A cultura jurídica moderna, inserida no paradigma cientificista da razão indolente apresenta por Boaventura de Sousa Santos, provoca o esvaziamento do papel dos atores sociais na criação do direito. Roberto Lyra Filho, na tentativa de superar esse obstáculo, propõe uma nova fundamentação dos direitos humanos mais próxima do processo concreto da humana libertação, e que não se localiza apenas nas declarações, mas no próprio processo histórico visto em sua totalidade e movimento. A concepção teórico prática de O Direito Achado na Rua demonstra que a apropriação do espaço público pelos movimentos sociais influência decisões políticas e ressignifica conceitos jurídicos, favorecendo a garantia de direitos e o acesso à justiça.

A experiência da luta contra a aids no Brasil mostrou que a garantia do acesso à justiça e do direito à saúde exige o alargamento do conceito de direito à saúde e adequada compreensão da relação entre saúde e preconceito. E que a discriminação não pode ser vencida através da ação judicial e de criação de lei e sem o enfrentamento do preconceito o direito à saúde e o acesso à justiça não podem ser plenamente garantido. 


\section{REFERÊNCIA BIBLIOGRÁFICA}

AGUIAR, Roberto Ramos de. O Direito Achado na Rua: um olhar pelo outro lado. In:

SOUSA JUNIOR, José Geraldo et al. Introdução crítica ao direito agrário (Série O

Direito Achado na Rua, v. 3). São Paulo: Imprensa Oficial do Estado, 2002.

BOURDIEU, Pierre. O poder Simbólico. Tradução: Fernando Tomaz. $8^{\mathrm{a}}$ edição. Rio de janeiro: Bertrand Brasil, 2005.

CAPPELLETTI, Mauro. GARTH, Bryant. Acesso à justiça. Porto Alegre: Fabris, 2002.

LYRA FILHO, Roberto. O que é Direito. São Paulo: Brasiliense, 1982.

LYRA FILHO, Roberto. Para um direito sem dogmas. Porto Alegre: Fabris, 1980.

MIRANDA, Adriana Andrade e GARCIA, Luciana Silva. Assessoria Jurídica em tempos de aids - a experiência do Gapa/Ba - Grupo de Apoio à Prevenção à AIDS. In: MENDES, Soraia da Rosa, org. Aids e direitos fundamentais: estratégias de efetivação dos direitos fundamentais de pessoas que (con)vivem com HIV. Porto Alegre: GAPA/RS, 2005.

MIRANDA, Adriana Andrade. Movimentos sociais, aids e cidadania. Dissertação de mestrado. UnB: 2007.

MEDEIROS, Robson Antão de, e QUEIROZ, Marcos Firmino de. O uso do direito pelo movimento social. in CÂMARA, Cristina e CARNEIRO, Cláudia M. de Paula. (Org.). O outro como um semelhante: direitos humanos e aids. Brasília: Ministério da saúde, CNDST/AIDS, 2002. 
ROCHA, José Cláudio. ALVES, Cristiano Cruz. O acesso à justiça: ao Poder Judiciário ou à ordem jurídica justa. Belo Horizonte: Revista Meritum Vol 6, n.01, 2011.

RUDNICKI, Dani. AIDS e Direito: papel do Estado e da sociedade na prevenção da doença. Porto Alegre: Livraria do Advogado, 1996.

SANTOS, Boaventura de Sousa. A crítica da Razão indolente: contra o desperdício da experiência. $3^{\text {a }}$ edição. São Paulo: Cortez, 2001.

Por uma concepção multicultural de direitos humanos. In: SANTOS, Boaventura de Sousa (org). Reconhecer para libertar: os caminhos do cosmopolitismo multicultural. Rio de Janeiro: Civilização Brasileira, 2003.

Para uma sociologia das ausências e uma sociologia das emergências. In: SANTOS, Boaventura de Sousa, (org.) Conhecimento Prudente para uma Vida Decente. São Paulo: Cortez, 2004.

SOUSA JR, José Geraldo de. Sociologia Jurídica: condições sociais e possibilidade teóricas. Porto Alegre: FABRIS, 2002.

Direito como Liberdade: O Direito Achado na Rua experiências emancipatórias de criação do direito. Brasília: UnB, 2008. Tese de Doutorado. VENTURA, Mirian. Direitos humanos e aids: o cenário brasileiro. Rio de Janeiro: ABIA, 1999.

SOUTO, Cláudio. O Direito Achado na Rua. In: SOUSA JUNIOR, José Geraldo et al. Introdução crítica ao direito agrário (Série O Direito Achado na Rua, v. 3). São Paulo: Imprensa Oficial do Estado, 2002. 